\title{
DGN-Forschungs- und Förderpreise - Bewerbungsfrist endet bald!
}

Im Rahmen der NuklearMedizin 2020 vom

22. bis 25. April 2020 in Leipzig werden

4 Forschungspreise verliehen. Noch bis

zum 15. Januar 2020 können Sie sich in der Geschäftsstelle der DGN um folgende Preise bewerben:
- Cuno Winkler-Preis

- Georg von Hevesy-Preis der DGN

- Förderpreis der DGN für Leistungen auf dem Gebiet der nuklearmedizinischen Therapie

- Sonderpreis der DGN zur Förderung der digitalen Transformation des Fachgebiets Nuklearmedizin
Bitte senden Sie Ihre Unterlagen als pdfDokumente fristgerecht per E-Mail an: office@nuklearmedizin.de.

Ausführliche Informationen zu den einzelnen Preisen und zu den Bewerbungsbedingungen erhalten Sie auf der DGN-Homepage www.nuklearmedizin.de in der Rubrik ; „Leistungen und Informationen/Forschungspreise“. 